\title{
¿Hablamos? Análisis del discurso y estrategias empleadas en WhatsApp por estudiantes universitarios
}

Should we speak? Analysis of the discourse and strategies used in WhatsApp by university students

\section{María José Molina García}

Universidad de Granada

Nưmero especial $-\mathbf{V I}-$

Investigación en enseñanza de lenguas desde una perspectiva global

2020
ONOMÁZEIN | Número especial VI - Investigación en enseñanza de lenguas desde una perspectiva global: 274 -294 DOI: 10.7764/onomazein.ne6.14

ISSN: 0718-5758

\section{(c) $($ i) $\Theta$}

María José Molina García: Facultad de Ciencias de la Educación y del Deporte (Melilla), Universidad de Granada | E-mail: mjose@ugr.es

Fecha de recepción: 25 de julio de 2018

Fecha de aceptación: 28 de diciembre de 2019 


\section{Resumen}

El presente estudio pretende detectar los hábitos, estrategias y características lingüísticas utilizados en el sistema comunicativo de WhatsApp, como red social de mayor número de usuarios, por los estudiantes de la Universidad de Granada (España) con una muestra de 342 conversaciones (198 de mujeres y 144 de hombres) ofrecidas por un total de 114 participantes a los que también se les aplica un cuestionario diseñado ad hoc para completar la información. El análisis de datos se hace por el programa estadístico SPSS (versión 22 para Windows) y el Parametrizador Morfológico de Textos (ParamText TIP) de Carreras-Riudavets y otros (2011). El estudio expone el uso que se hace de esta vía de comunicación y confirma que se emplea un lenguaje multimodal específico. También revela la existencia de algunas diferencias desde la perspectiva del género.

Palabras clave: comunicación social; WhatsApp; lingüística aplicada; perspectiva de género.

\section{Abstract}

This study aims to detect the habits, strategies and linguistic characteristics used in the WhatsApp communication system, as a social network with a greater number of users, by university students of the University of Granada (Spain) with a sample of 342 conversations (198 of women and 144 of men) offered by a total of 114 participants to whom an ad hoc questionnaire designed to complete the information is also applied. The data analysis is done by the statistical program SPSS (version 22 for Windows) and the Morphological Text Parameterizer (ParamText TIP) of Carreras-Riudavets et al. (2011). The study exposes the use made of this communication channel and confirms that a specific multimodal language is used. It also reveals the existence of some differences from a gender perspective.

Keywords: social communication; WhatsApp; applied linguistics; gender perspective. 


\section{Introducción}

El WhatsApp constituye, sin duda, un modelo de comunicación de referencia para la juventud española. Según el Estudio anual de redes sociales 2019, elaborado por el Interactive Advertising Bureau (IAB Spain), asociación que representa al sector de la publicidad y la comunicación digital en España, WhatsApp es la red con más usuarios en el país (88\%), ligeramente por encima de Facebook y a una distancia significativa de Youtube, Instagram y Twitter. El mismo estudio revela que el grado de satisfacción de los usuarios, de los cuales el 97\% confiesa utilizarlo a diario, se sitúa por encima de la media.

Esta vía de comunicación está tan extendida que la prensa se hace eco de noticias, de diversa índole y en distintas secciones, conocedora del interés que genera en un amplio número de consumidores. Así, tan solo en este último año se ha informado sobre innovaciones como "El acceso con huella dactilar y otras novedades de WhatsApp en este arranque de 2019" (sección nacional de El País del 15/1/2019) o que "WhatsApp trabaja para hacer nuestros vídeos más divertidos" (sección nacional de Cinco días del 8/8/2019); se han expuesto inconvenientes personales y profesionales, como, por ejemplo, "Vida nueva. Mantenemos grupos de WhatsApp que nadie sabe cómo dejar sin quedar mal con gente que en el fondo nos da igual” (columna de opinión de El País del 6/1/2019), "Sancionado un soldado español por no obedecer una orden por WhatsApp" (sección nacional de El País del 30/12/2018), “Despedido por difundir en WhatsApp un video de su superior haciendo deporte" (sección nacional de Cinco días del 4/9/2019), "Estos son los móviles que no podrán usar WhatsApp a partir de ahora” (sección de tecnología de $A B C$ de 2/7/2019), "WhatsApp e Instagram sufren una nueva caída” (sección nacional de El Periódico de 30/4/2019), "9 de cada 10 universitarios españoles usan el móvil en clase” (columna de AS de 19/9/2019); han publicado soluciones a algunos problemas derivados de su uso, tales como "Cómo saber cuál es el contacto que tienes más pesado en WhatsApp" (columna de Cinco días del 9/9/2019), "Cinco trucos básicos para blindar tu privacidad en WhatsApp" (columna de Cinco días del 18/9/2019) o "WhatsApp evitará que te añadan a un grupo sin tu permiso" (sección nacional de El País de 18/2/2019), e, incluso, noticias acerca de las consecuencias sobre posibles cambios sociales de comportamiento y actitud, como "Ya nadie coge el teléfono. Así hemos olvidado la cultura de la conversación" (columna de El País de 17/1/2019), entre otros.

Esta panorámica evidencia la presencia de un sistema en el entorno, con sus ventajas e inconvenientes, que necesita ser atendido y estudiado, desde el punto de vista lingüístico, como fenómeno social y comunicativo en el que están implicados también, como parte de la ciudadanía, los estudiantes universitarios, dado que asistimos a un modo evolucionado y particular de comunicación escrita que incluye no solo texto, sino también elementos audiovisuales (Cremades y otros, 2016) que podría clasificarse como medio terciario, puesto que recodifica la escritura convencional y, a su vez, implica una transcripción previa del habla (Crystal, 2008).

El estudio exploratorio que se presenta pretende indagar en el uso que los universitarios del Grado en Educación Primaria, como futuros docentes, hacen de esta herramienta de comuni- 
cación en su vida diaria para conocer mejor el código utilizado, sus características lingüísticas principales y si existen diferencias significativas desde el punto de vista del género para incorporarlo como sistema susceptible de ser estudiado y aplicado en las aulas.

\section{Bases teóricas}

\subsection{Impacto social de WhatsApp}

Según la etimología, la palabra WhatsApp proviene de la expresión inglesa what's up, frase coloquial que podría traducirse como “¿qué pasa?", a la que se le ha añadido el término app, habitual en cualquier aplicación de un medio digital (Calero Vaquera, 2014). No solo el vocablo, utilizado en español sin ninguna adaptación gráfica desde 2009, fecha de su primera aparición, está ya admitido por la RAE (2018) —aunque la magna institución recomienda el empleo de "wasap"-, sino que también lo está el verbo que designa su acción, "wasapear". Desde sus orígenes, el concepto que define es el de charlar, conversar, es decir, lo que en el mundo tecnológico se conoce como "chatear", esto es, dialogar de manera informal en entornos próximos al sujeto.

Sin embargo, lejos de circunscribirse a la discreción de lo privado, WhatsApp se ha convertido en un fenómeno de gran impacto social, digno de ser recogido en informes expertos del mundo digital, pues su estado y evolución afecta a un gran número de individuos. Así, el Estudio anual de redes sociales 2019, elaborado por el Interactive Advertising Bureau (IAB Spain), asociación que representa al sector de la publicidad y la comunicación digital en España, expone que es la red con más usuarios (88\%), que ha desbancado a otras como Facebook, Youtube, Instagram y Twitter. El mismo estudio asegura que un 97\% de los usuarios lo utiliza a diario con un grado de satisfacción superior a la media, lo cual augura larga vida al medio.

Las redes sociales, especialmente WhatsApp, son utilizadas a diario por siete de cada diez personas, según la edición de 2018 de La sociedad en red, informe anual realizado por la Secretaría de Estado para el avance digital del Ministerio de Economía y Empresa con un porcentaje de uso del 42,8\%. Por su parte, el Panel de Hogares de la Comisión Nacional de los Mercados y la Competencia (CNMC) indica que el uso diario de la mensajería instantánea supera otras vías más tradicionales hasta el extremo de duplicar en 2018 al de las Ilamadas por móvil, tal y como se comprueba en la tabla 1 (véase la tabla en la página siguiente).

Según la 21. aㅡㄴ Enesta AIMC (Asociación para la Investigación de Medios de Comunicación) a Usuarios de Internet, Navegantes en la Red, realizada en 2018, un 49.3\% de los sujetos encuestados confiesan no poder vivir sin internet en el móvil, cifra que ha aumentado desde 2013, año en el que comenzó este estudio anual. Asimismo, un 93.5\% declara utilizar WhatsApp como principal servicio de mensajería instantánea con una media de 30 minutos en cada intervención realizada. 


\section{TABLA 1}

Frecuencia de uso de las llamadas y mensajes mediante servicios de comunicación tradicionales y OTT

\begin{tabular}{lcccc} 
& NUNCA & $\begin{array}{c}\text { SEMANALMENTE } \\
\text { O MENOS }\end{array}$ & $\begin{array}{c}\text { CASI TODOS } \\
\text { LOS DiAS }\end{array}$ & $\begin{array}{c}\text { VARIAS } \\
\text { VECES AL DíA }\end{array}$ \\
\hline Llamar por teléfono fijo & $21.2 \%$ & $47.1 \%$ & $19.9 \%$ & $10.3 \%$ \\
\hline Llamar por teléfono móvil & $5.9 \%$ & $36.8 \%$ & $30.8 \%$ & $25.6 \%$ \\
\hline Enviar SMS por teléfono móvil & $59.2 \%$ & $32.2 \%$ & $3.9 \%$ & $2.0 \%$ \\
\hline $\begin{array}{l}\text { Enviar mensajes instantáneos } \\
\text { (whatsapp, etc.) }\end{array}$ & $14.1 \%$ & $7.0 \%$ & $15.2 \%$ & $62.0 \%$ \\
\hline $\begin{array}{l}\text { Llamar o vídeo llamar por internet } \\
\text { (whatsapp, skype, etc.) }\end{array}$ & $48.2 \%$ & $38.5 \%$ & $6.9 \%$ & $4.4 \%$ \\
\hline
\end{tabular}

Fuente: propia basada en datos de CNMC

Paralelamente, el fenómeno social es foco de atención de la prensa, en primer lugar, por el número de ciudadanos al que afecta y, en segundo lugar, por las noticias que genera de muy diversa índole (progresos, problemas, inconvenientes, advertencias, etc.), tal y como se apuntaba en la introducción de este trabajo.

Aunque todas las encuestas, estudios e informes recogen que este servicio de mensajería instantánea se encuentra cada vez más extendido a individuos de diferente edad (Padrón, 2013), resulta una seña de identidad entre los adolescentes, quienes, desde hace años, se comunican por y con el móvil para establecer relaciones sociales (Barrio y Ruiz, 2017). En su acceso a la universidad, continúan con este hábito, de forma que se ha convertido en el género escrito más utilizado como una nueva tipología textual (Gómez-del-Castillo, 2017) de gran calado y muy presente en sus vidas que conlleva la controversia de si dificulta o no el uso de la lengua culta.

Así, en el mundo anglosajón, mientras Powell y Dixont (2011) consideran que esta forma de escribir no influye en el inglés académico, De Jonge y Kemp (2012) no descartan que la pobreza lingüística presente en muchos de los universitarios de Reino Unido se deba a las disortografías de los llamados textismos o textos discrepantes con la norma. Paralelamente, en España, Gómez-Camacho y Gómez-del-Castillo (2015) tampoco atribuyen los errores ortográficos de los estudiantes a la utilización de WhatsApp, aunque inciden en que este lenguaje ha de ser incorporado al currículum para su análisis y estudio.

\subsection{Características discursivas de WhatsApp}

Las peculiaridades de la comunicación por WhatsApp (rapidez, espacio privado informal, dinamismo, espontaneidad, ubicuidad, sincronía, economía del lenguaje, etc.), además de la posibilidad de incluir recursos icónicos, generan un lenguaje multimodal específico y una 
ortotipografía singular a cuya semiótica contribuyen todos con el significado que aportan (Sampietro, 2016). La tipología textual resultante no es una mera suma de narración con diálogos, puesto que el discurso es impulsado y dominado por la interacción (Bernicot y otros, 2014), que no busca un fin estético, sino una continuidad en el relato (Vázquez-Cano y otros, 2015).

Este tipo de lenguaje ha sido calificado como "texto escrito oralizado" o "texto híbrido", porque se trata de una conversación escrita que permite, incluso, cierta digresión respecto a la norma. Calero Vaquera (2014) realiza una comparación exhaustiva con otros códigos digitales como SMS o Messenger a nivel supraestructural (con el análisis de sus elementos extratextuales), macroestructural (según sus elementos paratextuales) y a nivel microtextual (con respecto a los elementos intratextuales), de modo que es susceptible de ser estudiado y analizado desde el punto de vista lingüístico.

A todo ello se añade la presencia de emojis (ideogramas codificados ofrecidos por la propia aplicación), emoticonos con caracteres ASCII o, simplemente, emoticonos (construcciones de caracteres tipográficos que han de leerse con la cabeza inclinada), gifs, imágenes y videos, al alcance de los usuarios y que contribuyen a la comunicación.

Por otro lado, es posible conseguir información adicional sobre si los interlocutores están conectados y, en caso contrario, cuándo fue la última conexión, si el mensaje se ha enviado (chek), ha sido recibido (doble chek) y leído (doble chek azul).

Blanch y otros (2016) focalizan la atención en el desarrollo de ciertas destrezas para adquirir la competencia lingüística necesaria en la comunicación digital que supone WhatsApp. Estas destrezas se basan en un conocimiento de los formatos multimedia, así como de las expresiones lingüísticas utilizadas para una correcta interpretación. Ello lleva a una disminución considerable de las trasgresiones normativas del lenguaje WhatsApp entre jóvenes, respecto a adolescentes, lo cual enfatiza la idea de que sea necesario su tratamiento para tomar conciencia.

\section{Objetivos}

Con este estudio se pretende conseguir los siguientes objetivos:

- Estudiar la frecuencia de las categorías gramaticales en las conversaciones por WhatsApp de los estudiantes universitarios.

- Establecer las principales características y variaciones ortotipográficas.

- Conocer el procedimiento de uso de esta vía de comunicación entre los universitarios.

- Observar las diferencias según la variable sexo. 


\section{Metodología}

\subsection{Participantes}

Los participantes en el estudio son 114 estudiantes universitarios del Campus de Melilla pertenecientes a la Universidad de Granada (España) que cursan el segundo año (2018/2019) de la titulación de Educación Primaria en la Facultad de Ciencias de la Educación y del Deporte. Predominan las mujeres con $57.89 \%$ (66) frente a los hombres con $42.10 \%$ (48). La edad de los participantes oscila entre los 19 y 24 años, siendo la moda de 20.

\subsection{Instrumentos de recogida de datos}

El instrumento de la investigación, diseñado ad hoc y disponible en el anexo, consiste en un cuestionario que, además de solicitar la edad y sexo de los sujetos, plantea 18 preguntas abiertas y cerradas, de opción única o múltiple, y de variable nominal presentadas en dos apartados: el primero aborda aspectos sobre el uso habitual de WhatsApp (tiempo de conexión, características de los grupos a los que pertenece, etc.) y el segundo indaga sobre el componente lingüístico y comunicativo (temas, comportamientos ante malentendidos, ortotipografía, elementos visuales, ventajas e inconvenientes de este medio de comunicación, propuestas de mejora, utilización de otras redes, etc.). Para su validación se recurrió a juicio de expertos de diversas universidades españolas (Barcelona, Cantabria, Jaén, Uned y Granada), siguiendo los criterios de Skjong y Wentworth (2000) y las indicaciones de Escobar-Pérez y Cuervo-Martínez (2008). El procedimiento de recogida de estos datos ha sido a través de la tecnología de Google Forms preservando el anonimato.

Por otro lado, para elaborar el corpus de los mensajes de los informantes se les solicita el envío voluntario de tres chats de WhatsApp a una dirección de correo electrónico, haciendo uso de una función de la aplicación y asociando un número en clave para su procesamiento. Los criterios para seleccionar dichos chats han sido temporales (entre treinta y sesenta minutos de duración y escritos en un plazo no superior a un mes), formales (con un mínimo de tres dialogantes de entre 19-25 años del mismo sexo, cuyo principal conversador fuera el propio sujeto participante pero sin identificación de los nombres de los interlocutores) y de contenido (diversidad temática y con eventual presencia de emojis, imágenes o cualquier otro recurso icónico, así como de saludos y despedidas). Con todo ello se ha obtenido una muestra de 342 conversaciones (198 de mujeres y 144 de hombres).

\subsection{Métodos de análisis}

Se ha planteado una investigación cuantitativa para cuyo análisis se emplean dos herramientas informáticas: el programa estadístico SPSS (en su versión 22 para Windows) para las preguntas del cuestionario y el Parametrizador Morfológico de Textos (ParamText TIP) de Carreras-Riudavets y otros (2011), con el que se indaga en el contenido morfológico, léxico y 
discursivo de la muestra. Se ofrece también el número de palabras reconocidas y no reconocidas, así como la relación de otros elementos comunicativos presentes en WhatsApp.

\section{Resultados y discusión}

Tras parametrizar los textos recogidos, se comprueba, tal y como se recoge en la tabla 2, que el número de palabras utilizadas por los hombres es significativamente inferior al de las mujeres, además de que son las féminas las que demuestran mayor variedad en el empleo de términos diferentes, vocablos por oraciones y vocablos por párrafos. Estos datos corroboran los obtenidos por Barrio y Ruiz (2017) con estudiantes de la Comunidad Autónoma de Cantabria, Gómez-del-Castillo (2017) con titulados superiores y Gómez-Camacho y Gómez-del-Castillo (2017) con universitarios de posgrado.

\section{TABLA 2}

Número de palabras según la variable sexo

\begin{tabular}{lcc} 
& HOMBRES & MUJERES \\
Número de palabras & 2221 & 12005 \\
\hline Palabras diferentes & 944 & 2691 \\
\hline Oraciones & 431 & 2491 \\
\hline Párrafos & 404 & 2383 \\
\hline
\end{tabular}

Fuente: propia

Respecto a la categoría gramatical, el recuento de todos estos términos sigue una distribución ligeramente distinta, según el género, tal y como se recoge en la tabla 3. Así, aunque los sustantivos, seguidos de los verbos, sean los más empleados para ambos, en el caso de los hombres, el orden posterior es pronombres, adjetivos, adverbios, conjunciones, preposiciones y artículos, y en las mujeres, pronombres, adverbios, adjetivos, conjunciones, preposiciones y artículos.

La media de aparición por oración de estas categorías gramaticales es idéntica en ambos géneros, siendo 3 en el caso de los sustantivos; 2 para los verbos (aunque hay intervenciones en las que se omite por sobreentenderse o por haber sido utilizado de forma reciente), y I para adjetivos, adverbios, pronombres, preposiciones y conjunciones, sin que, necesariamente, aparezcan todos de manera simultánea. También en ambos géneros abundan entre los sustantivos los comunes, concretos e individuales, y, en el caso de los verbos, las formas más empleadas son la segunda persona del singular del presente de indicativo (183 en los hombres y 1044 en las mujeres), la segunda persona del singular del imperativo (140 en los hombres y 790 en las mujeres) y la primera persona del singular del presente de indicativo (132 en los hombres y 637 en las mujeres). 


\section{TABLA 3}

Frecuencia de la categoría gramatical según la variable sexo

\begin{tabular}{lcc} 
& HOMBRES & MUJERES \\
Sustantivos & 1272 & 6456 \\
\hline Verbos & 670 & 3737 \\
\hline Adjetivos & 441 & 2077 \\
\hline Adverbios & 332 & 2199 \\
\hline Pronombres & 443 & 2794 \\
\hline Preposiciones & 313 & 1381 \\
\hline Artículos & 194 & 1047 \\
\hline Conjunciones & 323 & 1952 \\
\hline No reconocidas & 77 & 516 \\
\hline
\end{tabular}

Fuente: elaboración propia

El concepto de No reconocidas alude a aquellas palabras que el parametrizador no reconoce morfológicamente o que están escritas en un idioma extranjero. En la tabla presentada a continuación se han clasificado en distintas modalidades y se muestran algunos ejemplos:

\section{TABLA 4}

Modalidades de palabras no reconocidas y sus variedades lexicales

\begin{tabular}{ll} 
Onomatopeyas & EJEMPLos \\
\hline Exclamaciones & $\begin{array}{l}\text { Jajaja (jajajaajjaa, jajjjajaj, jjjajaj...), jejeje, ajajá } \\
\text { (ajajajá, ajajjajaa...), puff, blablablá, uff, shhh... }\end{array}$ \\
\hline Diminutivos incorrectos & Uiiii, weeee, jooo, Dioooos, oleeee, eee, joé, usu... \\
\hline Coloquialismos/jergas & Diítas, chiqui, peli, holita... \\
\hline $\begin{array}{l}\text { Compuestos formales o } \\
\text { derivados incorrectos }\end{array}$ & Entanarnos, Aguadú, fosconear, veranuki.. \\
\hline Siglas/acrónimos & Cagoentodo, facetime, delegad@s... \\
\hline Nombres propios extranjeros & CCSS, PPT, NEE, finde... \\
\hline Diminutivos de nombres propios & Cristi, Fer, Moupest, Nihed, Cheima, Mustafa, \\
\hline Términos extranjeros & Power point, ok, erasmus, ready, blog, youtube, \\
& Word, merci, please, brother. perfect, shower... \\
\hline
\end{tabular}

Fuente: propia 
Esta relación lexicográfica está confirmada por otros estudios como el de Calero Vaquera (2014), Ortego Antón (2018) y Pérez-Savater (2015), entre otros.

Por otra parte, en esta muestra de conversaciones ofrecida por los sujetos participantes, se intercala un total de 8 imágenes en el caso de los hombres, y 30 en el caso de las mujeres, en forma de fotos, capturas de pantalla o videos que complementan las intervenciones. Ello confirma la nueva norma comunicativa y la caracterización de esta emergente tipología textual tratada en el marco teórico (Gómez-del-Castillo, 2017).

Respecto a la primera parte del cuestionario referida al uso de WhatsApp, la mayoría de los sujetos de la muestra declaran tener entre 5 y 10 grupos de WhatsApp operativos, aunque los porcentajes varían y, en el caso de las mujeres, 20 es el límite, al contrario del $12.5 \%$ de sus compañeros, que pueden tener más:

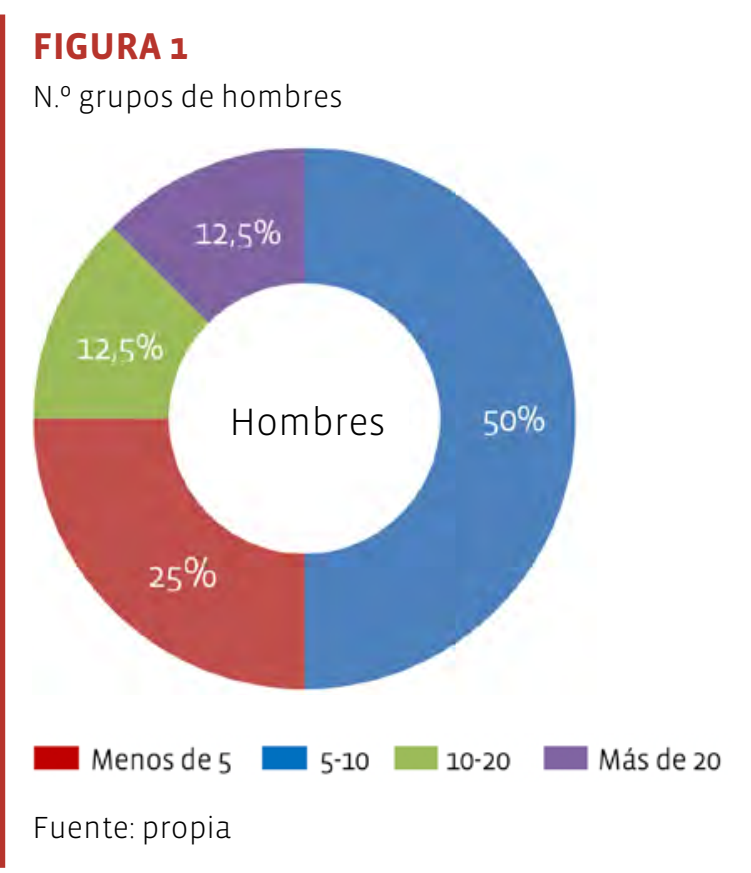

\section{FIGURA 2}

N. ${ }^{\circ}$ grupos de mujeres

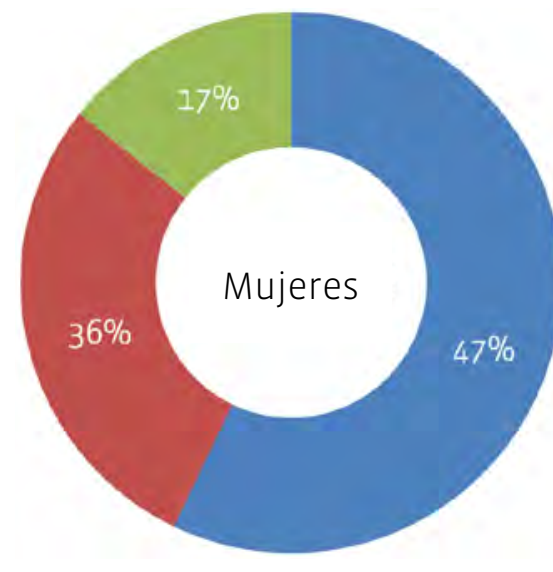

Menos de 5 5-10 10-20 Más de 20 Fuente: propia

Estos grupos están formados, de manera equitativa, por amigos y compañeros de estudios (ambos con un 62.5\%) en el caso de los hombres, seguido de miembros de alguna afición o deporte compartidos (37.5\%), familiares (25\%) y, por último, integrantes de algún viaje organizado (12.5\%); las mujeres prefieren los grupos de WhatsApp de familiares y amigos (90\% en ambos casos), seguidos muy de cerca de compañeros de estudios (82\%) y, por último y a gran distancia, de compañeros de trabajo (18\%) y de afición común (sobre todo, baile, con un 9\%). La comunicación por WhatsApp con fines académicos parece apoyar el estudio de FondevilaGascón y otros (2019) con estudiantes de la Universidad de Navarra, aunque, en el caso que nos ocupa, los familiares y amigos también están muy presentes. 


\section{FIGURA 3}

Integrantes en grupos de hombres

$100 \%$

Hombres

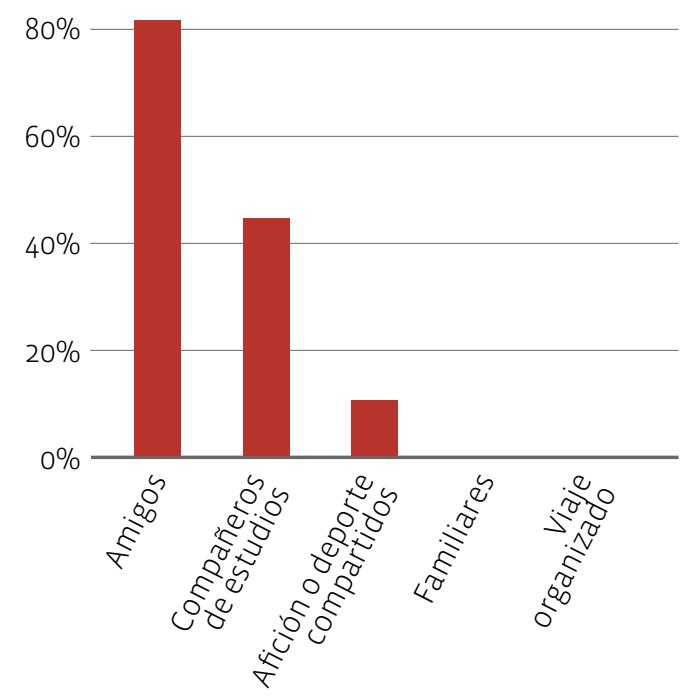

Fuente: propia

\section{FIGURA 4}

Integrantes en grupos de mujeres

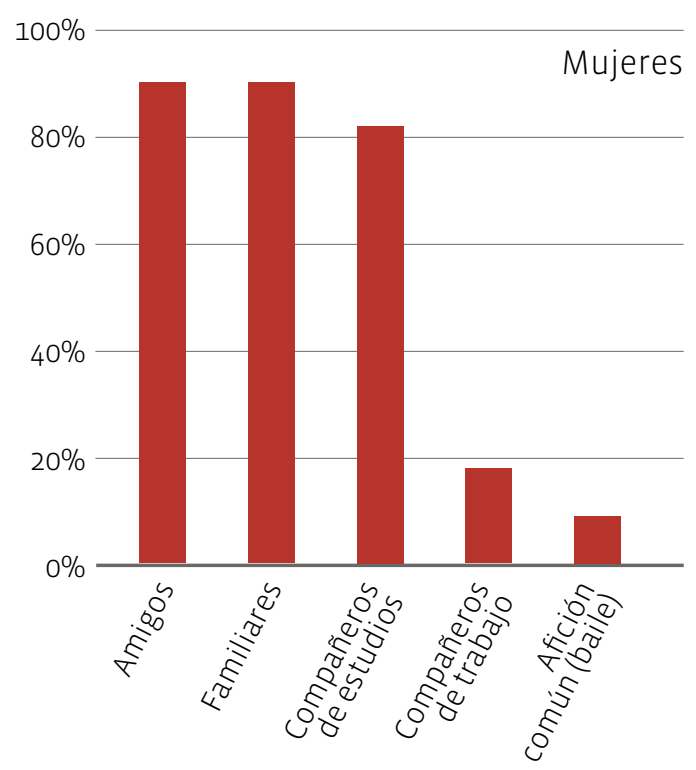

Fuente: propia

La denominación de los grupos no siempre sigue el mismo criterio aunque el principal, para ambos géneros, se base en una característica de ese grupo (un 87.5\% en los hombres y un 82\% en las mujeres). Los estudiantes utilizan una palabra inventada o una denominación graciosa (con un $12.5 \%$ ), de forma secundaria, mientras que un $45 \%$ de las estudiantes emplean una denominación graciosa o incluso un $11 \%$ otros criterios, como una forma cariñosa, una sigla o, incluso, un dato para recordar, pero nunca una palabra inventada.

El tiempo promedio de conversación tanto para hombres como para mujeres se sitúa entre media hora y una hora (87.5\% y 72\%, respectivamente), aunque en los primeros, el $12.5 \%$ restante declara utilizarlo entre 10 y 20 minutos pero nunca más de una hora, y en las segundas, un $20 \%$ confiesa estar más de una hora, y solo un $8 \%$, entre 10 y 20 minutos. La media de consumo difiere ligeramente de la recogida en la 21. ${ }^{a}$ edición del informe del AIMC (2018).

Respecto a las veces que utilizan WhatsApp al cabo del día, un 37.5\% de los participantes responde que más de 10 veces al día o cada vez que se necesita, mientras que un $12.5 \%$ entre 5 y 10 veces o solo por la noche. En el caso de las participantes, el 40\% lo hace cada vez que se necesita; un $18 \%$, más de 10 veces al día o solo por la tarde, y un 8\%, entre 5 y 10 veces o solo por la noche, o bien matizan otra respuesta como que depende de la época (si hay exámenes o en vacaciones, no se conectan apenas). En este aspecto, estos estudiantes presentan ciertas divergencias respecto a los estudiantes de la Universidad de Navarra (Fondevila-Gascón y otros, 2019), quienes confiesan utilizarlo más en franjas horarias nocturnas. 
La última cuestión planteada en esta primera parte del cuestionario pregunta a los sujetos de la muestra los motivos (pueden seleccionar más de uno) de utilización del WhatsApp. Los universitarios distribuyen sus respuestas entre por la rapidez y por la utilidad (37.5\%), porque se puede mantener la conversación con varias personas a la vez (25\%) y por la senciIlez, la eficacia o porque es cómodo para los integrantes (12.5\%). Además, en otros motivos, alegan razones como la gratuidad (25\%), estar tan extendido que su uso es necesario para estar al día o que permite estar conectado todo el día (12.5\%). Las universitarias, por su parte, se decantan por la utilidad (55\%), por la eficacia (37\%), por la rapidez (19\%) o por la sencillez (9\%), aunque añaden también otras razones como poder conectarse con gente de fuera (18\%) y la gratuidad o poder conectarse desde cualquier lugar (9\%). Algunos de estos argumentos, como el de la gratuidad, la eficacia, la comodidad y la rapidez, surgen en el estudio de Fondevila-Gascón y otros (2019).

La segunda parte del cuestionario pretende profundizar en el componente lingüístico y comunicativo de WhatsApp y, para ello, el primer aspecto abordado es la temática tratada por este medio, por lo que se ofrece la opción de respuesta múltiple. Los hombres prefieren conversar sobre estudios (62.5\%), ocio o cualquier tema que surja (50\%) y, en último lugar, temas familiares (12.5\%); las mujeres tratan, en primer lugar, temas de estudios (82\%), seguidos de familiares (73\%), ocio (55\%) y, en último lugar, trabajo (19\%). Sin embargo, añaden temas como el entorno y de actualidad (37\%) y no escogen la opción de cualquier tema. Este abanico de posibilidades que pertenece al mundo de los adultos está en sinergia con los postulados de expansión a todas las franjas de edad esgrimidos por Padrón (2013)

El 100\% de la muestra confiesa haber tenido un malentendido alguna vez por este medio de comunicación, pero el orden de vías para solventarlo (podían elegir más de una) varía. En el caso de ellos, prefieren hablarlo en persona (87.5\%), y solo porcentajes inferiores, una llamada de teléfono (15\%), seguir utilizando el WhatsApp (15\%) 0, incluso, correo electrónico o skype (12.5\%). La mayoría de ellas, sin embargo, recurren a una llamada de teléfono (73\%), seguida de hablar en persona (45\%), continuar utilizando el WhatsApp (28\%) o recurrir al correo o al skype (9\%), resultados similares a los expuestos por Gómez-del-Castillo (2017).

En cuanto al uso de otros medios de comunicación empleados a lo largo del día, en general, los chicos utilizan facebook (50\%), instagram o llamadas de teléfono (37.5\%), twittter (25\%) y SMS (12.5\%), mientras que las chicas prefieren facebook (55\%), Ilamadas de teléfono (45\%), twitter o instagram (37\%), correo electrónico (28\%), SMS pero también snapchap (18\%) y messsanger ( $9 \%)$, en consonancia con los informes y encuestas comentados en el marco teórico de este trabajo.

Interrogados acerca de qué emojis utilizan con más frecuencia, todos responden que las caras, en sus variados gestos (tristeza, alegría, carcajadas, asombro, tranquilidad, pensamiento, burla, enfado, besos...), los dedos de la paz, los dedos de la victoria, el pulgar hacia 
arriba y las manos rogando son los más empleados. En el caso de los chicos, el repertorio consta de 22 figuras, y en el caso de las chicas, de 35. Ellos añaden alguno relacionado con el deporte (por ejemplo, balón de fútbol) y también guiños, y ellas emplean, además, los corazones, las parejas o grupos, los animales y los aplausos. En cualquier caso, a la pregunta 15 acerca de cómo representarían determinadas emociones, todos los sujetos optan por estos símbolos, salvo cuando precisan de un grito o mostrar una alegría y una broma, que alternan también con exclamaciones y mayúsculas (para el grito), las onomatopeyas (para la alegría) y emoticonos (tipo ASCII) o imágenes graciosas con o sin mensaje incorporado (con la broma). En cuanto a las abreviaturas más empleadas, en la siguiente tabla se exponen las más utilizadas:

\section{TABLA 5}

Abreviaturas más frecuentes

\begin{tabular}{|c|c|}
\hline & EJEMPLOS \\
\hline \multirow{4}{*}{ Sustantivos } & Hst (historia) \\
\hline & Exmn (examen) \\
\hline & Vd/vdd (verdad) \\
\hline & Uni (universidad) \\
\hline \multirow[t]{2}{*}{ Verbos } & Tngo (tengo) \\
\hline & Va (vamos) \\
\hline Adjetivos & Jnts (juntos) \\
\hline \multirow[t]{2}{*}{ Pronombres } & $T(\mathrm{te})$ \\
\hline & $M(\mathrm{me})$ \\
\hline \multirow[t]{7}{*}{ Adverbios } & Mñn (mañana) \\
\hline & Tdv (todavía) \\
\hline & Tmb/tb (también) \\
\hline & Mb (muy bien) \\
\hline & Tmpco (tampoco) \\
\hline & Zii (sí) \\
\hline & Bn (bien) \\
\hline \multirow{3}{*}{ Conjunciones } & $P q$ (porque) \\
\hline & Aunqu (aunque) \\
\hline & Q/k (que) \\
\hline \multirow[t]{2}{*}{ Preposiciones } & $X($ por $)$ \\
\hline & Pa (para) \\
\hline
\end{tabular}




\begin{tabular}{ll} 
Sintagmas/expresiones & $\frac{T q \text { (te quiero) }}{\text { Xfiiii (por favor) }}$ \\
\cline { 2 - 2 } Esq (es que) \\
\hline Wolaa (hala)
\end{tabular}

Fuente: propia

Se observa cómo, en ocasiones, se amplía el número de grafías para enfatizar (xfiii), aunque ello suponga, a veces, añadir más letras a la palabra original (nop, zii o wolaa). Singularmente, tan solo los hombres incorporan a esta relación la utilización también de dos acrónimos anglosajones: LOL (Laughing Out Loud, es decir, "reírse a carcajadas") y ROLF (Rolling On Floor Laughing, cuya traducción es "caerse de la risa”). De igual manera, tan solo el 10\% de los hombres declara utilizar un tipo de emoticono, concretamente XD, para indicar alegría o risa.

Estas características ortotipográficas, referidas a los elementos gráficos con interpretación suprasegmental y epéntesis y duplicaciones de letras, son similares a las estudiadas por Vázquez-Cano y otros (2015) con adolescentes en edades comprendidas entre los 13 y 17 años de cinco centros de enseñanza secundaria españoles en cuyas conversaciones también aparecían asiduamente en un afán por buscar mayor expresividad en su discurso. También a las características escritas recogidas por Gómez-Camacho y Gómez-del-Castillo (2017) con estudiantes de posgrado.

Finalmente, se les ha pedido que expongan tres ventajas y tres inconvenientes, además de en qué mejorarían el sistema de comunicación de WhatsApp. Entre las ventajas, los sujetos de la muestra consideran que es gratuito, rápido, fácil de manejar, contiene más utilidades (video llamadas, llamadas, enviar fotos y vídeos), es instantáneo o inmediato, lo usa la mayoría de las personas, permite la comunicación con cualquier parte del mundo, mantener relaciones de amistad a distancia y reducir las distancias comunicativas, informa de la recepción del mensaje, puede saberse si la otra persona está conectada, se queda escrita toda la conversación, se pueden pasar conversaciones a otras personas, puede utilizarse en varios dispositivos y el grupo lo puede usar a la vez.

Entre los inconvenientes, alegan que puede provocar adicción, no es seguro conocer la identidad del receptor, no se puede utilizar sin conexión a internet, la gente lo puede usar de forma inadecuada (abusos, amenazas...), hay muchos malentendidos, se pierde la esencia de hablar en persona, quita horas de estudio, puede crear un mal hábito ortográfico, no permite enviar grandes archivos.

Algunas de estas ventajas e inconvenientes coinciden con las descritas por Rubio-Romero y Perlado (2015), que recogen datos de los estudiantes de la Universidad Antonio de Nebrija, quienes consideran que, aunque la comunicación presencial es indispensable, puede alter- 
narse perfectamente con la digital y esta, además, facilita el intercambio cuando algún interlocutor tiene problemas de timidez o los integrantes del grupo no se ubican en el mismo espacio geográfico. Coinciden también en que resulta eficaz por su inmediatez, pero también por la comodidad que supone continuar el diálogo a posteriori, si se precisa. Añaden, además, que es un buen medio para "hablar por hablar", esto es, ocupar el tiempo de ocio en mantener una conversación privada cuando se está solo a diferencia de otras redes sociales. Además, la posibilidad de compartir videos, imágenes supone una gran ventaja, al igual que declaran los estudiantes del presente estudio. Por otro lado, también esta muestra poblacional manifiesta interés por mantener medidas de seguridad ante la posible pérdida de privacidad.

Por último, aunque un 7\% de los usuarios indica que el sistema es inmejorable, la mayoría expone algunas propuestas de mejora de este sistema de comunicación, tales como la posibilidad de sincronizar mensajes para enviar a una hora determinada o a una persona en concreto, añadir un indicador de faltas de ortografía, más privacidad y protección de usuarios, que la propia aplicación bloquee si se detecta abuso psicológico o insultos, que se pueda enviar grandes archivos, poder encontrar y guardar a las contactos a través del nombre que se ponga sin necesidad de saber el número y permitir adecuar el formato a estilos personales.

\section{Conclusiones}

Sin duda, a la luz de los resultados obtenidos y expuestos, el WhatsApp es un sistema de comunicación muy presente en la vida de los estudiantes universitarios y, como tal sistema de comunicación, es imprescindible conocer para un lingüista cuál es la pragmática de su uso y la caracterización de su tipología textual con el fin de estudiarla en su aplicación, analizarla y describirla.

La peculiaridad más relevante, y comprobada tras el presente estudio, es que se trata de un texto oral, muy similar a la conversación, pero que se escribe y, por tanto, se sitúa en la intercesión de ambos códigos. Esto permite que comparta características conversacionales tales como la participación de varios miembros, el establecimiento de un turno de palabra sin excesivos solapamientos, la determinación de unos temas por tratar, una pseudoespontaneidad y, a su vez, la oportunidad de revisar lo escrito, una relativa permanencia temporal, etc. Todo ello unido a una base digital que lo dota de proyección hacia varias personas a la vez, que comparten o no espacio y/o tiempo, junto a la posibilidad de combinar herramientas y recursos (mensajes de voz, videollamadas, envío de imágenes, videos...), además de la necesidad de cierta inmediatez que prescribe la situación. Con la sinergia de todas estas circunstancias, era inevitable que esta vía de comunicación articulara y determinara un lenguaje específico.

En el caso de la muestra aportada por los estudiantes, las universitarias generan mensajes mucho más extensos que sus compañeros y con mayor variedad de palabras. En ambos casos, la categoría gramatical más numerosa en las conversaciones por WhatsApp es el sustantivo, 
seguido del verbo (aunque, en ocasiones, este se omita). Desde la perspectiva del género, el orden continúa con los adjetivos para los hombres y los pronombres para las mujeres. Ello indica que el discurso se aproxima al género narrativo y, en sintonía con la temática abordada en su contenido y el contexto de sus actos de habla, abundan los verbos conjugados en presente de indicativo (primera y segunda persona) y en imperativo (segunda persona) además de los sustantivos concretos, comunes e individuales. Sin embargo, la espontaneidad a la que se aludía, el tono coloquial imperante y el ritmo en la dinámica de las intervenciones generan un lenguaje específico que se caracteriza, de forma singular, por la aparición de onomatopeyas, exclamaciones, coloquialismos jergales y extranjerismos de moda, siglas/acrónimos, abreviaturas (admitidas o no), así como por la licencia para el uso de términos lingüísticos incorrectos y no normativos, incluso de elementos icónicos (emojis, emoticonos, imágenes, vídeos...). Entre los primeros no se hallan diferencias de empleo por género, aunque sí en estos últimos, como se expone en el apartado de resultados.

Esta ortotipografía es muy relevante y constituye una seña de identidad hasta el punto de que no parece una conversación por WhatsApp si no integra algunos de estos elementos. También es variada y creativa, pues no solo se utilizan signos, abreviaturas, emojis y emoticonos ya codificados, sino que, en cualquier momento, el actante puede generar un signo que logre estandarizarse con el uso y la difusión, creando tendencia.

Respecto a la utilización de WhatsApp, aunque los hábitos sean, en general, similares, también se observan ciertas disparidades, según el género, en el número de grupos operativos (algunos hombres pueden participar hasta en el doble que sus compañeras), en la preferencia de sus integrantes, en el criterio para seleccionar la denominación otorgada a dichos grupos, en el tiempo promedio de conversación, el número de veces de conexión e incluso en los motivos que conducen a su empleo.

En cuanto al componente lingüístico y comunicativo, también las preferencias temáticas o los emojis, emoticonos y abreviaturas de su código presentan matices y tendencias de género en algunos casos.

Todos los sujetos participantes reconocen ventajas e inconvenientes y, por supuesto, propuestas de mejora para continuar utilizando este sistema comunicativo, puesto que, a pesar de que conviven con otras vías (redes sociales, correo electrónico o skype), su primera opción y la más extendida es siempre WhatsApp.

\section{Bibliografía citada}

ABC, 2 de julio de 2019: "Estos son los móviles que no podrán usar WhatsApp a partir de ahora” [recuperado de https://cutt.ly/DeZrJM8]. 
AIMC, 2018: Estudio General de Medios octubre 2017-mayo2018 (EGM), Madrid: AIMC- Asociación para la Investigación de Medios de Comunicación.

AS, 19 de septiembre de 2019: "9 de cada 10 universitarios españoles usan el móvil en clase" [recuperado de https://cutt.ly/qeZuj81].

Barrio Fernández, Ángela, e Isabel Ruiz Fernández, 2017: "Hábitos de uso del whatsapp por parte de los adolescentes", INFAD. Revista de Psicología 1, 23-40.

Bernicot, Josie, Antonine Goumi, Alain Bert-Erboul y Olga Volckaert-Legrier, 2014: "How do skilled and less-skilled spellers write text messages? A longitudinal study", Journal of Computer Assisted Learning 30, 559-576.

Blanch, Montserrat, Sonia Betancort y Mayra Martínez, 2016: "El videoblog en el aula de lengua y literatura de secundaria. Una propuesta práctica”, REICE. Revista Iberoamericana sobre Calidad, Eficacia y Cambio en Educación 14 (3), 33-49.

Calero Vaquera, María Luisa, 2014: "El discurso del Whatsapp: entre el Messenger y el SMS", Oralia 17, 85-114.

Carreras-Riudavets, Francisco, Juan Carlos Santana-Herrera, Zenón, Hernández-Figueroa y Gustavo Rodriguez-Rodriguez, 2011: Parametrizador morfológico de textos - ParamText TIP [recuperado de http://tulengua.es].

Cinco días, 8 de agosto de 2019: "WhatsApp trabaja para hacer nuestros vídeos más divertidos" [recuperado de https://cutt.ly/VeZuci3].

Cinco días, 4 de septiembre de 2019: "Despedido por difundir en WhatsApp un video de su superior haciendo deporte" [recuperado de https://cutt.ly/leZuQpH].

Cinco días, 9 de septiembre de 2019: "Cómo saber cuál es el contacto que tienes más pesado en WhatsApp" [recuperado de https://cutt.ly/ıeZuE6t].

Cinco días, 18 de septiembre de 2019: "Cinco trucos básicos para blindar tu privacidad en WhatsApp" [recuperado de https://cutt.ly/QeZuYyu].

Comisión Nacional de los Mercados y la Competencia, 2018: Panel de Hogares, Barcelona: CnMC.

Cremades, Raúl, Eugenio Maqueda y Juan L. Onieva, 2016: "Posibilidades didácticas de la escritura digital ubicua en la aplicación WhatsApp Messenger”, Revista Letral 16, 106-120.

CRYSTAL, David, 2008: Txtng: El Gr8 Db8, Oxford: Oxford University Press. 
De Jonge, Sarah, y Nenagh Kemp, 2012: "Text-message abbreviations and language skills in high school and university students", Journal of Research in Reading 35 (1), 49-68.

El País, 30 de diciembre de 2018: "Sancionado un soldado español por no obedecer una orden por WhatsApp" [recuperado de https://cutt.ly/VeZuUV3].

El País, 6 de enero de 2019: "Vida nueva. Mantenemos grupos de WhatsApp que nadie sabe cómo dejar sin quedar mal con gente que en el fondo nos da igual" [recuperado de https:// cutt.ly/2eZuSTK].

El País, 15 de enero de 2019: "El acceso con huella dactilar y otras novedades de WhatsApp en este arranque de 2019" [recuperado de https://cutt.ly/zeZuFOT].

El País, 17 de enero de 2019: "Ya nadie coge el teléfono. Así hemos olvidado la cultura de la conversación” [recuperado de https://cutt.ly/ıeZuHg1].

El País, 18 de febrero de 2019: "WhatsApp evitará que te añadan a un grupo sin tu permiso" [recuperado de https://cutt.ly/aeZuKqb].

El Periódico, 30 de abril de 2019: "WhatsApp e Instagram sufren una nueva caída” [recuperado de https://cutt.ly/NeZuLEH].

Escobar-Pérez, Jasmine, y Ángela Cuervo-Martínez, 2008: "Validez de contenido y juicio de expertos: una aproximación a su utilización”, Avances en medición 6 (1), 27-36.

Fondevila-Gascón, Joan Francesc, Joaquín Marqués-Pascual, Pedro Mir-Bernal y Marc Polo-López, 2019: "Usos del WhatsApp en el estudiante universitario español. Pros y contras", Revista Latina de Comunicación Social 74, 308-324.

Gómez-Camacho, Alejandro, y María Teresa Gómez-del-Castillo, 2015: "Escritura ortográfica y mensajes de texto en estudiantes universitarios”, Perfiles Educativos 37 (150), 91-104.

Gómez-del-Castillo, María Teresa, 2017: "Utilización de WhatsApp para a Comunicacón en Titulados Superiores”, Reice. Revista Iberoamericana sobre Calidad, Eficacia y Cambio en Educación $15(4), 51-65$

IAB, 2019: Estudio anual de redes sociales 2019, IAB Spain y Elogia.

Ortego Antón, María Teresa, 2018: “La alternancia del español al inglés en la comunicación académica de los estudiantes de traducción hispanohablantes a través de las redes sociales”, Onomázein 41, 108-124. 
PAdrón, Carmen Janeth, 2013: "Estrategias didácticas basadas en aplicaciones de mensajería instantánea WhatsApp exclusivamente para móviles (mobile learning) y el uso de la herramienta para promover el aprendizaje colaborativo", Eduweb 7 (2), 123-134.

Pérez-Savater, Carlos, 2015: "Discovering language variation in WhatsApp text interactions", Onomázein 31, 113-126.

Powell, Daisy, y Marc Dixont, 2011: “Does SMS text messaging help or harm adults'knowledge of standard spelling?”, Journal of Computer Assisted Learning 27 (1), 58-66.

RAE, 2018: Libro de estilo de la lengua española, Madrid: Espasa.

Rubio-Romero, Juana, y Marta Perlado Lamo de Espinosa, 2015: "El fenómeno Whatsapp en el contexto de la comunicación personal: una aproximación a través de los jóvenes universitarios", Icono 14 (13), 73-94.

Sampietro, Agnese, 2016: "Emoticonos y multimodalidad. El uso del pulgar hacia arriba", WhatsApp. Aposta. Revista de Ciencias Sociales 69, 271-295.

Secretaria de Estado para el Avance Digital, 2018: La sociedad en red. Informe anual 2017, Ministerio de Economía y Empresa, Gobierno de España.

SkJong, Rolf, y Benedikte H. Wentworth, 2000: “Expert Judgement And Risk Perception”, Det Norske Veritas. Noruega [recuperado de https://cutt.ly/3rylJbW].

Vázquez-Cano, Esteban, Santiago Mengual-Andrés y Rosabel Roig-Vila, 2015: "Análisis lexicométrico de la especificidad de la escritura digital del adolescente en WhatsApp", Revista de Lingüística Teórica y Aplicada 53 (1), 83-105.

\section{ANEXO}

\section{Cuestionario}

\section{CONOCIMIENTO Y USO DE WHATSAPP}

Desde la Universidad de Granada (España) se está llevando a cabo una investigación sobre conocimiento y uso de WhatsApp. Por ello, le solicitamos su colaboración garantizándole el anonimato de sus respuestas, cumpliendo así con lo establecido en las leyes sobre secreto estadístico y protección de datos personales. El cuestionario que le presentamos para cumplimentar está organizado en tres secciones (la primera recoge algunos datos sociodemográficos; la segunda se refiere al uso que usted hace del WhatsApp y la tercera sirve para indagar sobre las características lingüísticas y comunicativas de este medio). 
Es importante que responda a todas ellas y que lo haga con total sinceridad, para realizar de forma adecuada el análisis de los resultados obtenidos.

Agradecemos de antemano su colaboración con esta investigación.

\section{DATOS PERSONALES}

Sexo $\square$ Mujer $\square$ Hombres

Edad (años cumplidos):

\section{USO DE WHATSAPP}

1. ¿Cuántos grupos de WhatsApp operativos tiene?

a. Menos de 5

b. De 5-10

c. De $10-20$

d. Más de 20

2. ¿Quiénes componen la mayoría de sus grupos de WhatsApp? (puede elegir varias opciones)

a. Familiares

b. Amigos

c. Compañeros de estudios

d. Todos

3. ¿Qué criterio sigue para denominar a un grupo? (puede elegir varias opciones)

a. Una palabra inventada

b. Una característica de ese grupo

c. Compañeros de estudios

d. Todos

4. ¿Qué tiempo promedio de conversación suele ocupar una sesión de WhatsApp?

a. Entre 5-10 minutos

b. Entre 10-20 minutos

c. Media hora

d. Una hora

e. Más de una hora

5. ¿Cuántas veces, aproximadamente, utiliza WhatsApp al cabo de un día?

a. Entre 5 y 10 veces

b. Más de 10 veces al día

c. Solo por la mañana

d. Solo por la tarde

e. Solo por la noche

f. Otro...

6. ¿¿¿Por qué utiliza WhatsApp? (puede elegir varias opciones)

a. Por la rapidez

b. Porque se puede mantener la conversación con varias personas a la vez

c. Porque es cómodo para los integrantes

d. Otros motivos... 


\section{COMPONENTE LINGÜISTICO Y COMUNICATIVO DEL WHATSAPP}

8. ¿Qué temas suele tratar por WhatsApp? (puede elegir varias opciones)

a. Familiares

b. De trabajo

c. De estudios

d. De ocio

e. Cualquier tema

f. Otros

9. ¿Ha ocurrido algún malentendido por esta vía?

a. Sí

b. No

c. No lo recuerdo

d. Otros

10. Si alguna vez ocurre un malentendido, ¿cómo lo resuelve? (puede elegir varias opciones) a. Seguimos utilizando el WhatsApp para las explicaciones oportunas

b. Se buscó una vía alternativa de comunicación para aclarar la situación

c. Se habla en persona

d. Otras

11. ¿Qué otro medio utiliza para comunicarse a lo largo del día? (puede elegir varias opciones)

12. ¿Qué emojis utiliza con más frecuencia?

13. ¿Qué abreviaturas o siglas utiliza con más frecuencia?

14. ¿Emplea algún emoticono? En caso afirmativo, ¿cuál o cuáles?

15. ¿Cómo representaría...?
a. Una broma:
b. Una ironía:
c. Un sarcasmo:
d. Un grito:
e. Miedo:
f. Alegría:
g. Disgusto:

16. Enumere tres ventajas de WhatsApp respecto a otro medio de comunicación:

17. Enumere tres inconvenientes de WhatsApp respecto a otro medio de comunicación:

18. ¿En qué mejoraría el sistema de WhatsApp? 